\title{
A New Octanuclear Copper(II)-Nucleoside Wheel
}

\author{
Donatella Armentano, ${ }^{a}$ Teresa F. Mastropietro, ${ }^{a}$ Miguel Julve, ${ }^{b}$ Rachele Rossi, ${ }^{\text {a }}$ Patrizia \\ Rossi, ${ }^{\mathrm{c}}$ Giovanni De Munno* ${ }^{\mathrm{a}}$
}

${ }^{a}$ Dipartimento di Chimica, Università della Calabria, via P. Bucci 14/c, 87030 Arcavacata di Rende, Cosenza, Italy; ${ }^{b}$ Dipartimento di Energetica, Università di Firenze, via Santa Marta 3, 50134 Firenze; ${ }^{c}$ Departament de Química Inorgànica/Instituto de Ciencia Molecular, Facultat de Química de la Universitat de València, Polígon de la Coma s/n, 46980 Paterna (València), Spain;

\section{Supporting Information}

Analytical data for compound 1: Yield about 65\%. Anal. Calcd for $\mathrm{C}_{82} \mathrm{H}_{132} \mathrm{Cu}_{9} \mathrm{~F}_{30} \mathrm{~N}_{24} \mathrm{O}_{88} \mathrm{~S}_{10}$ : C 22.77, H 3.08, N 7.77, S 7.41. Found: C 22.34, H 2.95, N 7.49, S 7.61. The amount of water was confirmed by Thermogravimetric Analysis (TGA). The magnetic measurements on a polycrystalline sample of $\mathbf{1}$ were carried out with a SQUID device in the temperature range 295$1.9 \mathrm{~K}$ under an applied magnetic field of $1 \mathrm{~T}$. The magnetization measurements of the same sample of 1 were performed at $2.0 \mathrm{~K}$ in the field range 0-5 T. K Diamagnetic corrections were estimated from Pascal's constants. Experimental susceptibilities were also corrected for the temperature independent paramagnetism $\left[\begin{array}{lllll}60 & \times & 10^{-6} & \mathrm{~cm}^{3} & \mathrm{~mol}^{-1} \text { per } \mathrm{Cu}(\mathrm{II})\end{array}\right]$ and for the magnetization of the sample holder. X-band EPR spectra of a polycrystalline sample of $\mathbf{1}$ were carried out with a Bruker ELESYX instrument in the temperature range 285-4.0 K.

\section{$\underline{\text { X-ray Crystallography Details }}$}

The data were collected with a Xcalibur3 4 circles diffractometer, using monochromatized $\mathrm{CuK}_{\alpha}$ radiation. They were collected over the range $4.15^{\circ}>\theta>49.62^{\circ}$ and corrected for absorption. Data were processed using the SHELXTL package (SHELXTL; Bruker Analytical X-ray Instruments, Madison, WI, 1998). Solution and refinement were performed through the programs SHELXS97 (Sheldrick, G. M. Acta Crystallogr., Sect. A 1990, 46, 467) and SHELXH97 (Sheldrick, G. M. SHELXL-97. Program for the Solution and Refinement of Crystal structures; University of Göttingen: Germany, 1997). Crystal data for $\mathrm{C}_{82} \mathrm{H}_{132} \mathrm{Cu}_{9} \mathrm{~F}_{30} \mathrm{~N}_{24} \mathrm{O}_{88} \mathrm{~S}_{10}$, Orthorhombic, $\mathrm{a}=20.4591(9), \mathrm{b}=21.318(1), \mathrm{c}=36.871(2) \AA, \mathrm{V}=16081(1) \AA 3, \mathrm{~T}=293(2) \mathrm{K}$, space group $\mathrm{P} 2{ }_{1} 2_{1} 2_{1}, \mathrm{Z}=4, \rho=1.786 \mathrm{~g} / \mathrm{cm}^{3}, \mu=3.787 \mathrm{~mm}^{-1} .47448$ reflections measured, 15447 unique. Least-square refinement based on 12573 reflections with $\mathrm{I}>2 \sigma(\mathrm{I})$ and 1779 parameters 
led to convergence with final $\mathrm{R} 1=0.0789, \mathrm{wR} 2=0.2110$. Crystallographic data for the structure reported in this paper have been deposited with the Cambridge Crystallographic Data Centre as supplementary publication no. CCDC 627273.

Copies of the data can be obtained free of charge on application to CCDC, 12 union Road, Cambridge CB2 1EZ, UK (fax: (+44) 1223- 336-033; e-mail: deposit@ccdc.cam.ac.uk). 


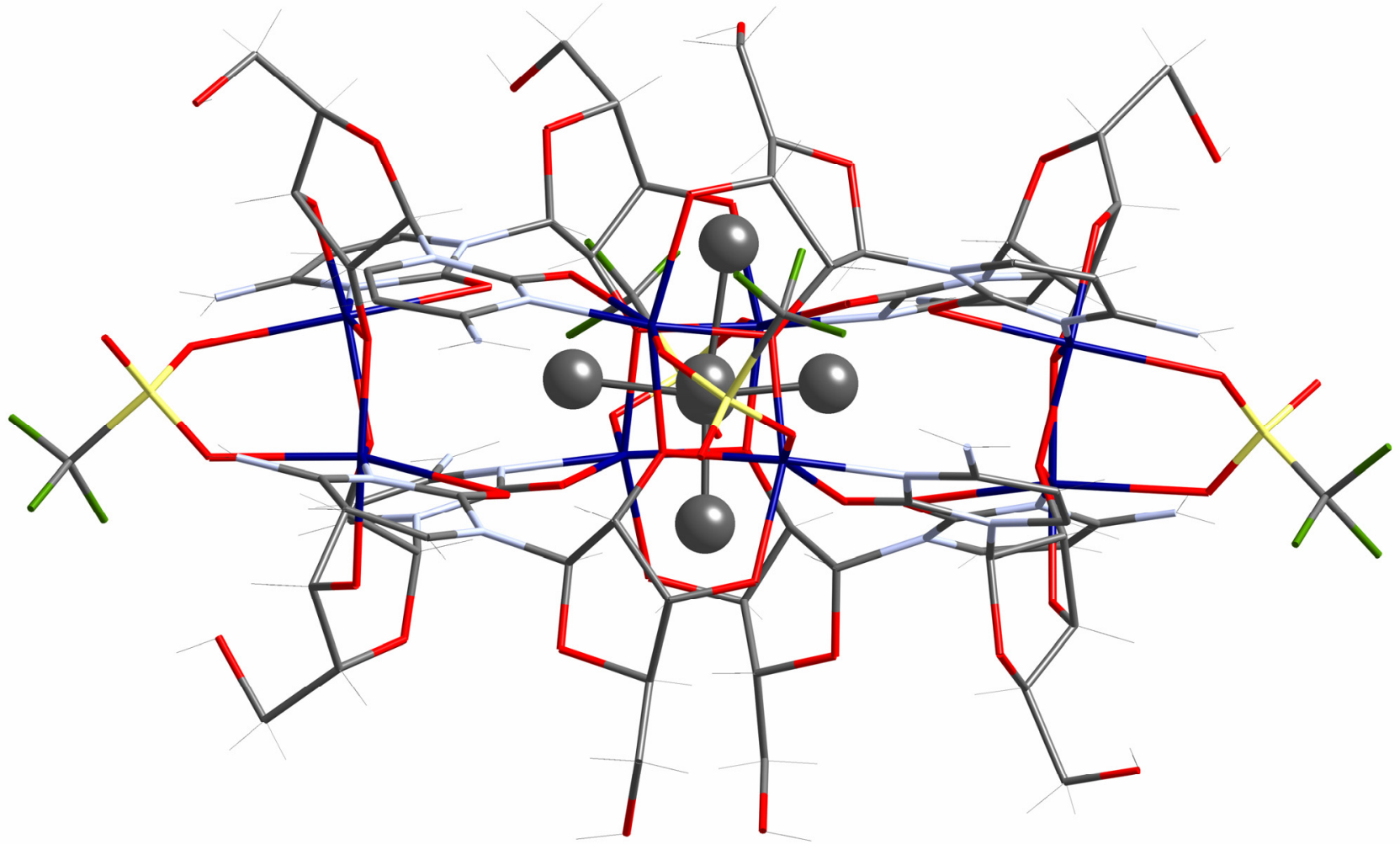

Figure S1. View along the $c$ axis of a octanuclear $\left[\mathrm{Cu}_{8}(\mathrm{Hcyd})_{8}\left(\mathrm{CF}_{3} \mathrm{SO}_{3}\right)_{4}\right]^{4+}$ unit showing the inclusion of the mononuclear $\left[\mathrm{Cu}\left(\mathrm{H}_{2} \mathrm{O}\right)_{6}\right]^{2+}$ entity. 


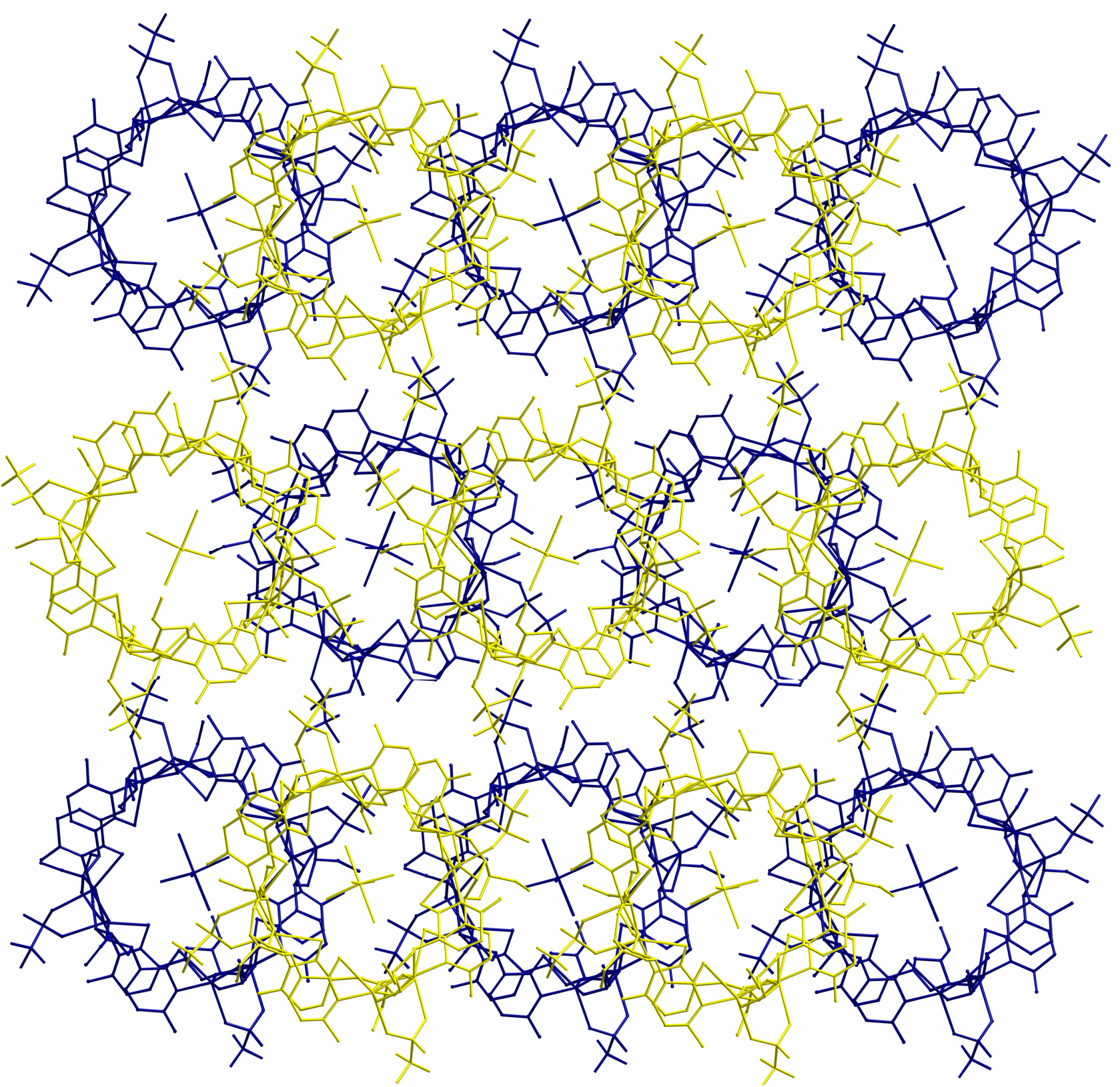

Figure S2. View of two stacked layers (noted with different colours) of complex $\mathbf{1}$ growing in the crystallographic $a c$ plane. 


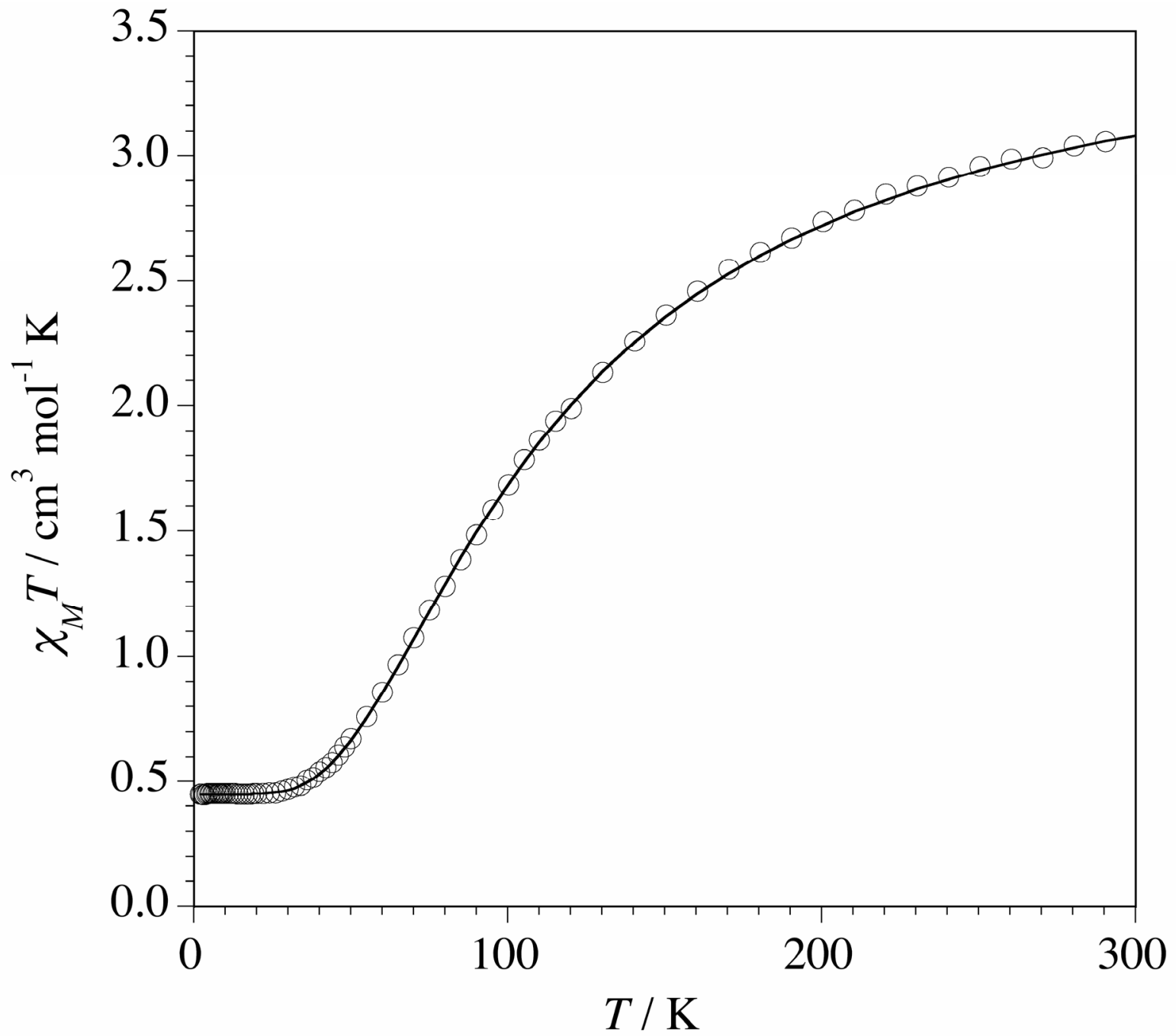

Figure S3. $\chi_{\mathrm{M}} T$ versus $T$ plot for 1 : (o) experimental data; (-) best-fit curve through eq (1)

$$
\chi_{M}=4\left\{\frac{2 N \beta^{2} g_{d}^{2}}{k T[3+\exp (-J / k T)]}\right\}+\frac{N \beta^{2} g_{m}^{2}}{4 k T}
$$

which corresponds to four equivalent dinuclear copper(II) complexes ( $J$ being the singlet-triplet energy gap within each dinuclear unit) plus a Curie law for a magnetically isolated spin doublet. 


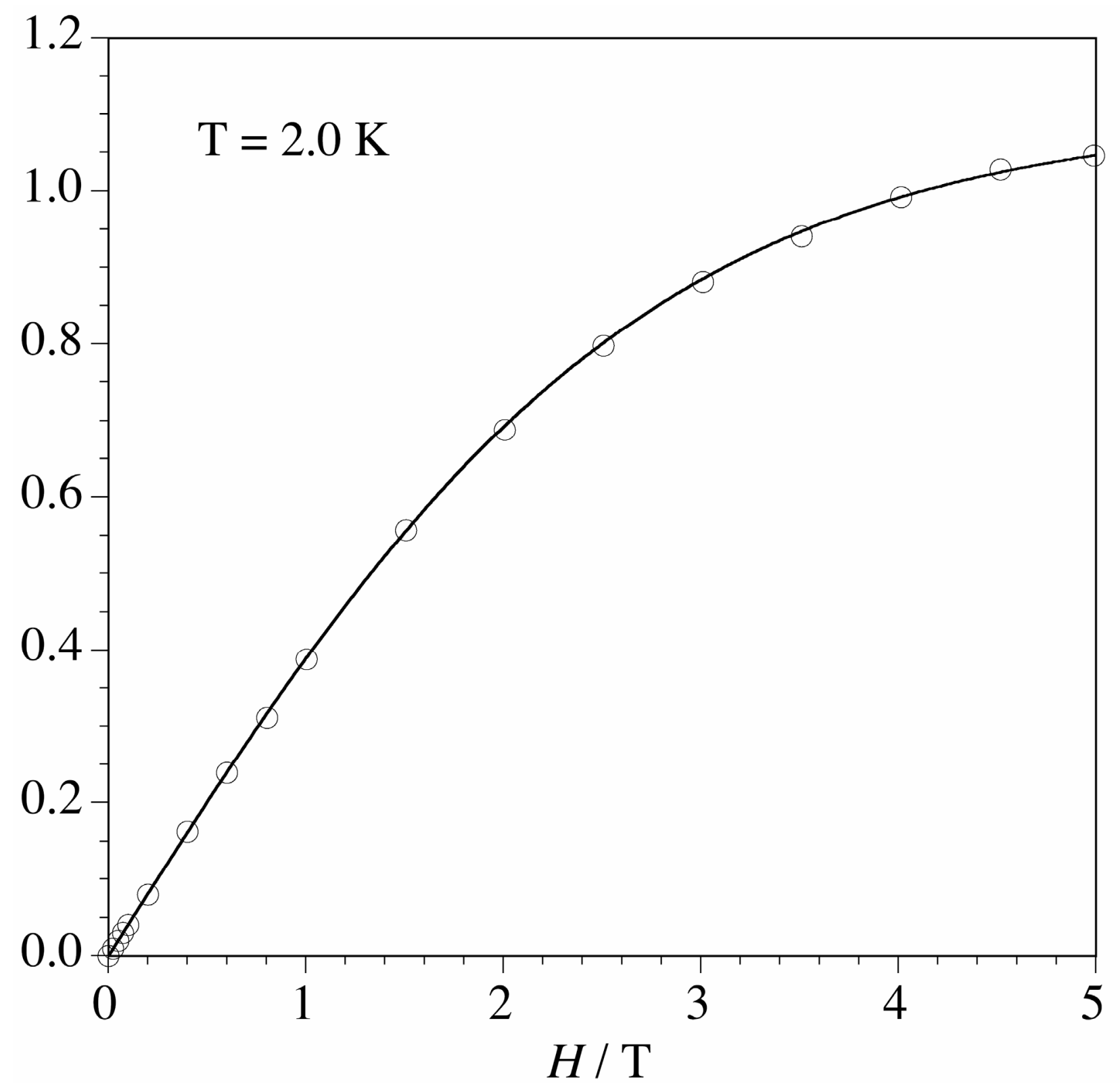

Figure S4. Magnetisation versus $H$ plot for 1 at $2.0 \mathrm{~K}$ : (o) experimental data; (-) Brillouin function for a magnetically isolated spin doublet with $g=2.20$. 


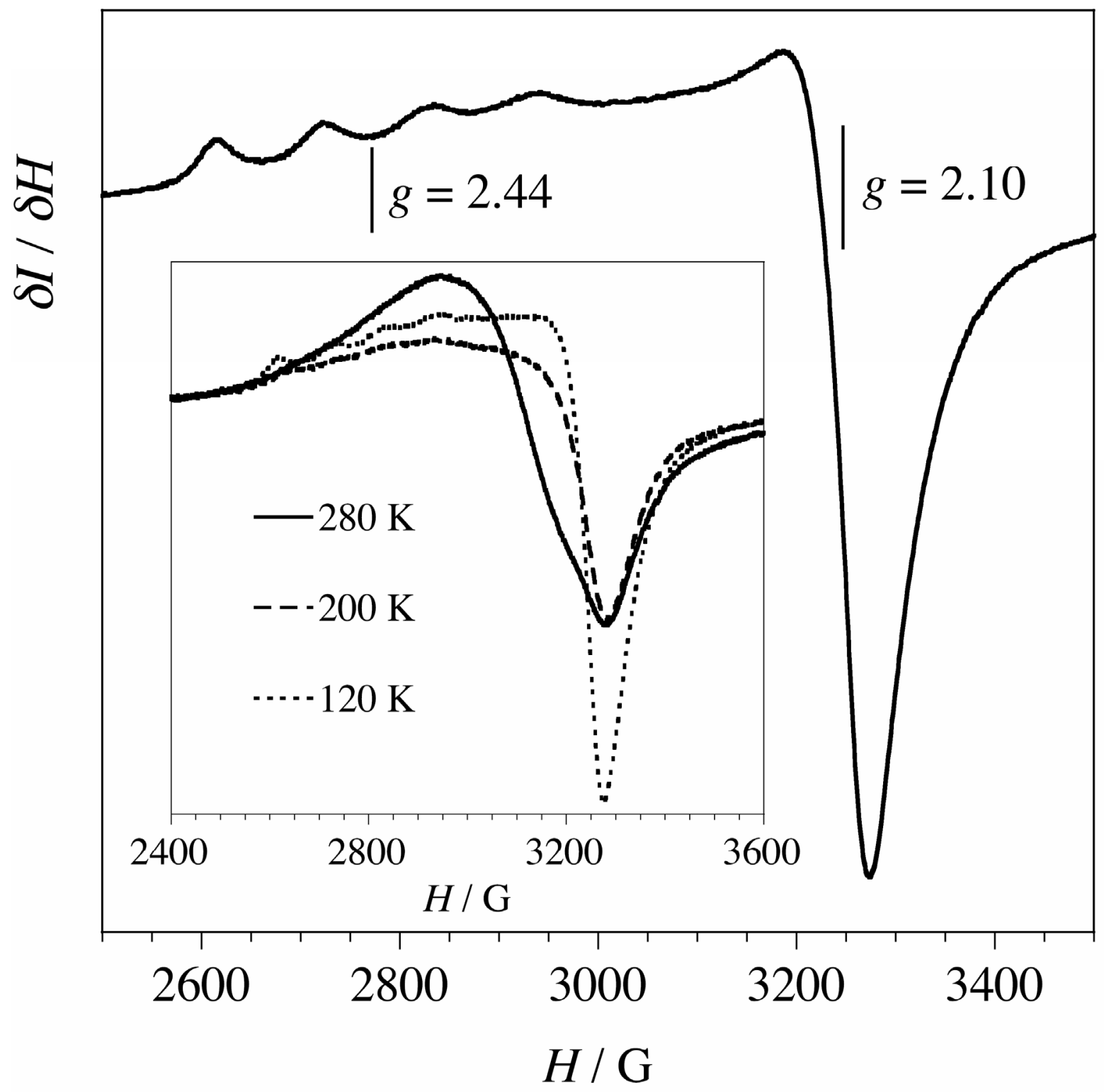

Figure S5. X-band EPR spectrum for a polycrystalline sample of $\mathbf{1}$ at $30 \mathrm{~K}$. The inset shows the EPR spectra of $\mathbf{1}$ at 280,200 and $120 \mathrm{~K}$. 